\title{
GUIMARÃES, ANA MARIA AGRA. A ENCENAÇÃO REAL: A SUBLIMAÇÃO EM A PAIXÃO SEGUNDO G.H. E ÁGUA VIVA, DE CLARICE LISPECTOR. BRASÍLIA: EDITORA UNIVERSIDADE DE BRASÍLIA, 2015. $172 \mathrm{p}$.
}

\author{
Andréia Guerini \\ Universidade Federal de Santa Catarina, Florianópolis, Santa Catarina, Brasil \\ andreia.guerini@gmail.com
}

Antônia de Jesus Sales

Instituto Federal de Educação, Ciência e Tecnologia do Ceará, Fortaleza, Ceará, Brasil antonia_saless@hotmail.com

Em $A$ Encenação do Real, Guimarães trata do conceito de sublimação nas obras Água Viva (1973) e A paixão segundo G. H. (1979), de Clarice Lispector. O conceito "sublimação" foi, inicialmente, discutido por Freud e, posteriormente, revisto por Lacan, em "sua relação com a pulsão de morte e com o vazio instalado pela ausência do objeto absoluto do desejo" (GUIMARÃES, 2015, p. 7). Guimarães discute G. H. e sua experiência transgressora no campo linguístico e a poética da morte em Água Viva.

$\mathrm{Na}$ introdução, temos a discussão da relação entre literatura e psicanálise, porque para a autora, investigar essa interface é, de certa forma, avançar no campo dos estudos da linguagem. E os teóricos utilizados são Freud e Lacan, porque discutem a psicanálise de forma interdisciplinar: enquanto Lacan relaciona estética e psicanálise, Freud aborda a arte e a psicanálise. Assim, ao longo dos quatro capítulos deste livro, a autora dialoga com Freud e Lacan a partir da análise de A paixão segundo G. H. e Água Viva.

No primeiro capítulo, "A experiência originária: a paixão pela transgressão", a autora analisa a transgressão da personagem de A Paixão Segundo G. H., na qual a personagem principal precisa encontrar uma linguagem adequada e própria para expressar sua experiência imprópria:

\footnotetext{
O relato de G. H. trata de uma experiência do Real. A arte moderna visa a atingi-lo, ao aparecimento de algo que não encontra espaço na realidade socialmente compartilhada. Visa, enfim, à falta, ao furo, ao vazio. Ao romper com a função mimética, a arte moderna põe em relevo o descentramento do sujeito, visceralmente, inadequado aos papéis e máscaras sociais, irredutível a uma interpretação plena. Esse sujeito procura modos de apresentação de sua singularidade. A arte moderna, portanto, irá voltar-se para uma pesquisa de linguagem que possa anunciar a desordem desse sujeito. (GUIMARÃES, 2015, p. 20)
}

Para embasar sua análise, Guimarães se utiliza do ensaio Sobre o Sinistro, de Freud (1919), O grau zero da escritura, de Roland Barthes (1984), o seminário 20 Mais ainda, de Lacan (1982). A autora defende que por não haver coincidência entre a linguagem e a realidade, tal fato tem como consequência o inconformismo do sujeito. Dessa forma, "a linguagem não substitui o mundo, nem ao menos o representa fielmente; pode apenas evocá-lo por meio de um pacto (...)" (GUIMARÃES, 2015, p. 20), e, assim, "a literatura moderna se apresenta

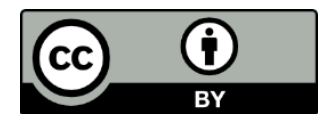


historicamente como um movimento radical de negação e afirmação da arte." (GUIMARÃES, 2015, p. 27)

No contexto da literatura, a autora recorre ao conceito de forclusão para embasar seu estudo. Forclusão foi um termo desenvolvido por Lacan para conceituar o sistema de defesa da mente. Assim, a tensão constante da personagem em G. H. é um mecanismo de defesa que a afasta da loucura, transformando o que foi vivido em algo que a personagem consegue narrar, transmitir, através da escritura. Nesse sentido, "a literatura como lugar do acolhimento recebe a experiência de G. H. para devolvê-la a outros, que, como ela, jogam-se quase nus na existência, na violenta experiência de viverem separados da própria vida, clivados pela linguagem. (...)" (GUIMARÃES, 2015, p. 29).

Já o conceito de sublimação é um ponto crucial na análise de Guimarães. A sublimação é oriunda da falta. Pela falta, se constrói algo. Pelo vazio de algo, se promove uma reelaboração. Para Lispector (1979, p. 180 apud GUIMARÃES, 2015, p. 36) "a realidade é a matéria prima, a linguagem é o modo como vou buscá-la - e como não a acho. Mas é do buscar e não achar que nasce o que eu não conhecia, e que instantaneamente reconheço. A linguagem é o esforço humano."

Dessa forma, a linguagem, para Lispector é um recurso que existe como materialização ou ausência de algo ao mesmo tempo, corroborando com o conceito de sublimação em Lacan.

No contexto de A paixão segundo G. H., o conceito de linguagem é algo constante e ausente ao mesmo tempo, articulando-se com o conceito de sublimação de Lacan (1986). Assim:

\begin{abstract}
A literatura moderna aponta para o indizível, mas sabe-la indizível faz dela um lugarcausa do desejo. É isso o que nos diz G.H. A linguagem é a fundadora da carência, tendo, portanto, sua mesma estrutura. É plenitude vazia e, por isso, presta-se para anunciar o destino humano: destino fundado pela carência. G.H. aceita e acolhe o impossível da linguagem como forma maior de maturidade. A carência é passagem para o sublime, carência do ser, carência da literatura, incapaz de nomear a totalidade do Real da linguagem. Dessa forma, G.H., ao apresentar sua experiência, também a rasura (GUIMARÃES, 2015, p. 37).
\end{abstract}

Para Lacan, a obra de arte se constrói e se organiza ao redor do vazio e a sublimação acaba evidenciando a existência desse vazio, uma vez que se tenta evitá-lo. O fato de G.H. ser arquiteta supõe também a existência de um vazio, ela cria um espaço novo e fica claro esse vazio quando essa descreve sua casa ao afirmar que o apartamento a reflete, pelo oco criado no espaço, da reverberação de telhas e o reflexo que os prédios vizinhos causavam em seu apartamento. Assim, o apartamento, por suas características, personifica a ausência existente também na vida da personagem. A questão da passagem do espaço, do apartamento ao quarto da empregada nos mostra, segundo Guimarães, uma travessia, uma transgressão que nos leva a perceber o quarto como um espaço de liberdade, no qual ocorre a passagem do luxo para a pobreza da empregada.

Já o encontro de G.H. com a barata representa um momento de encontro com sua subjetividade, pois “(...) Nesse encontro com a raiz das coisas, G.H. passa a experimentar tudo que ao humano não é permitido. $\mathrm{O}$ ato de matar lhe parece pleno de alegria. (...)" (GUIMARÃES, 2015, p. 42), e aqui a violência e a ferocidade alcançam uma beleza monstruosa. Ao comer a barata, o eu lírico come a própria vida, numa relação próxima de contato com o extinto, consumindo a própria vida. Nesse sentido: 
"O processo de inclusão do outro, da barata, por incorporação oral, é contra a natureza humana. Experiência transgressora de gozo e de acesso ao desconhecido de si. Tratase de um processo de uma violência inconcebível, feita a tudo que no ser aparece no domínio rígido, do já constituído e solidificado (...)” (GUIMARÃES, 2015, p. 43).

Ao escrever seu drama existencial, G.H. denuncia sua incompletude como sujeito. Dessa forma: "sua relação com a ordem simbólica é mantida, embora os significantes constituintes dessa ordem passem por um processo de negação e uma consequente reestruturação para suportar o sentido mudo de sua própria vivência.” (GUIMARÃES, 2015, p. $45)$.

A dor do existir funciona, assim, como mola propulsora para movimentar o desejo. Para Lacan, a sublimação acarreta uma experiência única. Ao ser possuída por um desejo de destruição, ao se voltar contra "a vida humanizada demais" (LISPECTOR, 1979, apud GUIMARÃES, 2015, p. 46). "O mundo humanizado demais é o mundo domesticado pela palavra, por seu uso social e ideológico, que corrompe o sentido, automatizando-o." (GUIMARÃES, 2015, p. 46).

Guimarães esboça, assim, uma contradição existente na obra A Paixão Segundo G.H.: um desejo de ter uma experiência absoluta de completude e impossibilidade dessa. Segundo Guimarães, Clarice joga com esta ambiguidade, o que provoca uma dificuldade de interpretação da obra. "Na narrativa clariciana, segundo Guimarães (2015, p. 49), "a ambiguidade é um poder ativo, produtor simultaneamente de sentido e de não sentido, elaborador de suas próprias normas, mas paradoxalmente incapaz de dar conta das normas que elabora." Guimarães considera que "A própria literatura é o discurso do Outro, que interpela a consciência e é por ela interpelado." (p. 57)

No capítulo 2, "A sublimação: uma via para a escritura", Guimarães afirma que: "O relato de G.H. é uma escritura de abertura, que mina e desestabiliza o cânone literário e o próprio poder do Outro." (p. 65) Tal experiência ocorre pela mediação da linguagem para a experimentação do real. Nesse sentido, (...) A escrita sublimatória é aquela que desnuda as ilusões, sabendo que a própria linguagem é também uma ilusão (GUIMARÃES, 2015, p. 66).

Guimarães, em seguida, elabora perguntas para balizar a construção de sua análise: "Que nome dar ao que G.H. viveu? Como relacionar o episódio da barata às questões que Clarice Lispector suscita em A paixão segundo G.H.? E por que quis transmutar em significante a experiência para o qual não há significante?” (p. 70), questionando, assim, se a identidade da personagem se dissolve pela vivência do acontecimento principal, no momento da escritura. Pois:

Nesse ato de dissolução de sua composição imaginária, os deslocamentos metonímicos de G.H. deslizam todos em busca de uma escritura condizente com sua experiência - uma escritura tensa, manifestação plena de negatividade. Nesse ato de narrar, o desejo de viver em estado bruto cede lugar ao gosto da pulsão. Sua transgressão da lei se transforma em transgressão da escrita. (GUIMARÃES, 2015, p. 70)

Lacan formaliza três registros de linguagem: o real, o imaginário e o simbólico. A personagem de Clarice experiência uma linguagem no limite do real e do simbólico. A autora pontua também a dificuldade da literatura em nomear experiências inomináveis e insólitas da vida, já que a vida não é plenamente capturável. Sobre a escrita sublimatória, Guimarães afirma: "O que nos chega é pela palavra, mas não toda palavra, senão por uma palavra "não-toda", 
aberta, fraturada, silenciosa, misteriosa.” (p. 74) Assim, a escrita sublimatória não pretende dizer tudo, pois se considera imperfeita, fragmentada e carente.

Ao comer a barata, G.H. retira a distância entre quem observa e o ser observado. Pela sua descrição de vivência, Clarice mostra a literatura como uma auto-negação. Guimarães chega, assim, a uma definição de escrita sublimatória:

\begin{abstract}
A escrita sublimatória é um significante denunciador da existência da castração simbólica e do vazio que advém da perda da Coisa, vazio radical que essa escritura vem presentificar. A sublimação não tem outra função senão permitir ao ser se referir à Coisa, ou seja, colocá-lo entre o Real e o significante. O que há no centro do intervalo é o vazio. Dessa escritura que contorna o vazio, advém um gozo para além do gozo fálico, que se produz no limiar de um furo. Porque o acesso ao objeto absoluto é impossível, a sublimação renova a carência e eterniza a falta com a qual goza. (...) (GUIMARÃES, 2015, p. 75)
\end{abstract}

No capítulo 3, "O esgarçamento da representação", Guimarães se debruça sobre as características da escrita sublimadora. "Sua Escrita se sustenta nesse jogo do não dizer tudo. É uma escritura tensa porque cava, no espaço da obra, espaço para a ausência de sentido, para a instabilidade. (...)" (p. 109). Nessa escrita, G.H. almeja repassar para o seu leitor um pouco da loucura e da transgressão vivida em sua experiência.

Guimarães pontua que:

(...) O texto clariciano não é reafirmador da potência do ser e da linguagem; antes, busca mostrar sua fratura, a fratura do ser, a fratura da linguagem, apontando para um sentido de negatividade, de incompletude. Essa literatura não se oferece como um produto capaz de tamponar a falta constitutiva do sujeito e da linguagem, mas, sim, trabalha no sentido de fazer surgir a negação da expressão, para que o inexpressão se torne, em si mesmo, força de expressão (GUIMARÃES, 2015, p. 121).

O texto clariciano constitui-se de um texto de autorreflexão, que se mostra sempre insuficiente e precário, comprometida com o lado trágico da linguagem, da vida e da literatura. Essas três partes trazem, em si, o vazio e não apontam para uma centralidade.

Nesse capítulo ainda, Guimarães faz uma relação entre as obras A paixão segundo G.H. e Água Viva. Em ambas as obras, as narradoras abordam a impossibilidade de expressão e a escritura se apresenta como um fator que as acolhe: "A escritura porque é vazia, pode suportar o vazio do desejo" (GUIMARÃES, 2015, p. 112).

Em ambas as obras, há "a própria condição inconsciente da palavra em seu fluxo e refluxo. A força de sua enunciação provém de seu próprio desfalecimento" (GUIMARÃES, 2015, p. 112). Assim, "suspensa por dois pontos, a narrativa anuncia, ao mesmo tempo, sua pretensão de captar o instante vivido e a impossibilidade de aprendê-lo." (GUIMARÃES, 2015, p.113). Dessa forma, coexiste uma tentativa de teatralizar o fazer da escrita e um desejo de desmistificar o ato literário.

No capítulo 4, "O gozo pulsional: a paixão pelo informe", Guimarães compara $A$ paixão segundo G.H. e Água Viva. Em ambas a palavra persiste e em ambas, temos a pulsão. Dessa forma, "O que advém dessa relação do desejo com a pulsão é o descentramento do sujeito, que, consequentemente, manterá com a linguagem uma relação também descentrada." De acordo com Guimarães:

A escritura sublimatória mantém um amor intenso pelo que é fragmento pelo que é descontínuo, pelo vazio e o indizível da linguagem, o que implica um profundo 
esforço para não cair no abismo absoluto do silêncio ou da loucura. A arte sublimatória é audaciosa no seu desejo de tocar o Real. Entretanto, só se constrói como arte quando mantém uma relação com o Simbólico. (...) (GUIMARÃES, 2015, p. 147)

Guimarães afirma que a arte personifica nossa incompletude como sujeitos e na conclusão destaca a experiência desagregadora, vivida por G.H., como um relato que a personagem deseja compartilhar, por não conseguir encadear sua narrativa em um processo de produção de sentido, G. H. passa a considerar a impossibilidade da representação.

Para concluir, podemos dizer que o fato de investigar o real em duas obras complexas de Clarice Lispector, pelo viés psicanalítico, enriquece a crítica clariciana. Novas análises de cunho interdisciplinar, como a proposta por Guimarães, são úteis necessárias para ampliar do leque de compreensão de uma obra literária, em geral, e das obras analisadas, em particular.

\section{Referência}

GUIMARÃES, A. M. A. A Encenação do Real: A sublimação em A paixão segundo G. H. e Água Viva, de Clarice Lispector. Brasília: Editora Universidade de Brasília, 2015. 172 p.

Recebido em: 23 de outubro de 2020 Aceito em: 10 de novembro de 2020

Publicado em Dezembro de 2020 